\title{
REVISITANDO A \\ AMAZÔNIA DE CARLOS CHAGAS
}

\author{
REVISITING \\ CARLOS CHAGAS' AMAZON
}

Quando pensamos em revisitar as regiões da Amazônia que Carlos Chagas percorreu entre outubro de 1912 e março de 1913 tínhamos clareza de que o tempo, matéria essencial da história, seria o centro de nossas preocupações. O que motivou a pesquisa foi o desejo de observar um mesmo espaço em dois tempos distintos, de modo a comparar as condições atuais de vida e saúde nos vales dos rios Solimões e Juruá, Purus e Acre, Negro e Branco, com aquelas encontradas por Carlos Chagas oito décadas atrás. O cientista deixou suas impressões registradas em um diário de campo, e num relatório prefaciado por Oswaldo Cruz, que foi encaminhado a Pedro de Toledo, ministro da Agricultura, Indústria e Comércio (Cruz, 1913). Este havia solicitado, através da Superintendência de Defesa da Borracha, um plano de profilaxia para evitar que a malária continuasse a dizimar os seringueiros. A expedição de Chagas gerou, também, um acervo fotográfico com mais de trezentas peças, cujo autor permanece desconhecido (Albuquerque; Alves; Benchimol; Santos; Santos; Thielen; Weltman et alii., 1991).

A análise deste material nos levou a pensar que as informações presentes nas imagens eram mais ricas do que as registradas em texto. Enfocavam temas diferentes, como a flora, o meio ambiente, as habitações da população. Realçavam questões sociais pouco exploradas pelo cientista, ou validavam diagnósticos como este: "é no rio Negro que se encontra a condição mais primitiva de trabalho, a menor atividade nos serviços de extração da borracha e as mais precárias condições de vida humana. Daí a pobreza tradicional deste rio, e a grande decadência que é dado observar em todos os seus centros populosos. Nele, o índice endêmico pelo impaludismo é elevadíssimo, havendo a agravante da ausência absoluta de assistência médica" (Cruz, 1913, p. 34).

Decidimos, então, revelar a história que se desenrolou a partir das realidades documentadas naquelas imagens, e escolhemos o vídeo como suporte para o resgate da memória popular, para o registro de informações atuais e a constituição de um acervo que subsidiasse o trabalho analítico. Usamos também a fotografia para complementar os registros informativos e, principalmente, para estabelecer comparações entre os dois tempos.

Os temas de maior ocorrência no conjunto fotográfico de 1913 são as paisagens rurais e fluviais e os transportes. Rios, barrancos e vegetações emolduram vultos de vapores, gaiolas e embarcações menores, denotando a vastidão do território, a dificuldade de percorrê-lo e a escassa presença humana. São freqüentes as paisagens de vilas e povoados onde se podem discernir casas, roupas e hábitos de seus habitantes. Merecem destaque as imagens de Manaus, símbolo da riqueza da borracha. 
O objeto principal da investigação realizada por Chagas eram as doenças que grassavam na região. Homens e crianças com baços volumosos aparecem com os órgãos internos afetados pela malária em destaque por meio de desenhos feitos pelo médico em seus corpos. Cabeças, pernas e braços com enormes feridas documentam as devastações da leishmaniose.

A visão que orienta as fotografias feitas na Amazônia pela Comissão Oswaldo Cruz descortina um território onde a natureza extasia e a doença forma um mundo novo e desconhecido. Os cientistas de Manguinhos retrataram uma Amazônia enferma, mas, ao mesmo tempo, carregada de potencial econômico para a República. Textos e imagens reiteram a idéia de que, combatidas as doenças que vitimavam os habitantes da região, através de uma ação firme e decidida do governo, ela se transformaria em paraíso.

Para os membros da comissão, as condições de vida das populações locais eram determinadas pelas enfermidades, pela falta de assistência médica, pelo tipo de trabalho executado e a alimentação. $O$ rio Negro era o menos produtivo dos vales visitados porque aliava a maior escassez de trabalhadores brancos aos mais elevados índices endêmicos, principalmente de malária e ancilostomose. Era uma região empobrecida, doentia, povoada por um "gentio indolente e sem ambição" (op. cit., 1913, p. 31). Ali, o homem só poderia viver e prosperar se interviesse o conhecimento médico, transformando-o em força de trabalho produtiva (Thielen, 1992).

Ainda hoje, o vale do rio Negro abriga múltiplas etnias em diferentes graus de aculturação e integração com a sociedade nacional, nações indígenas de famílias lingüísticas distintas - tucano, aruaque e macu - com várias formas de contato intertribal. Europeus e brasileiros vieram inscrever neste emaranhado seus quinhões de cultura (Santos e Lima,1991; Galvão, 1979; Souza,1977).

Ao diminuírem as distâncias que os separavam da 'civilização', os povos indígenas foram empurrados para fora de suas culturas nativas sem, contudo, usufruírem os benefícios da urbanidade que serviu de parâmetro à aculturação. Mergulharam, ao contrário, nas mais opressivas condições de vida e saúde impostas por este processo. Os contatos com os colonizadores europeus começaram a se estreitar em meados do século XVII. A criação da capitania de São José do Rio Negro estabeleceu um vínculo político entre os habitantes da região e a Coroa portuguesa, abrindo caminho para a série de iniciativas patrocinadas pelo poder colonial. Intensificou-se a afluência de colonos interessados na economia extrativista que se consolidava, mas só em 1853 se tentou organizar o fluxo, criando-se colônias de africanos livres e com imigrantes trazidos de Portugal, da Espanha e China (Loureiro, 1989, p. 37; Reis, 1965, pp. 35-40).

No final do século XIX, o movimento migratório era totalmente dominado pelos nordestinos que fugiam das secas devastadoras do sertão. Demandavam, quase sempre, os vales dos afluentes da margem sul do Solimões, os chamados 'rios borracheiros'. Por ser um rio onde quase não vingou a produção de borracha, o Negro ficou menos exposto ao processo de integração entre sociedade nacional e grupos étnicos amazônicos. Ainda assim, declinaram as culturas ancestrais dos povos que ali viviam, por força dos deslocamentos para novos contextos sociais.

Todavia, a realidade que encontramos em alguns destes lugares nos faz supor que muitos grupos lograram atingir razoável equilibrio entre suas formas tradicionais de vida e os novos padrões sócio-econômicos que lhes foram impostos. Ao chegarmos em Massarabi (17.8.1995), encontramos uma comunidade bem organizada com cerca de sessenta pessoas. 
Seus líderes têm uma visão interessante do deslocamento cultural pelo qual passaram, e avaliam de maneira positiva as possibilidades que hoje se apresentam para o seu cotidiano. Pertencem à tribo baré, que já morou em Maturacá mas foi desalojada pelos ianomâmi. Praticam agricultura diversificada e desfrutam de condição razoável de saúcle.

Os habitantes de Massarabi aprenderam a lidar com a sociedade moderna sem esquecer as suas tradições. Cultivam a história ancestral de seu povo por meio de relatos orais e compõem harmonioso mosaico cultural com seus rituais, lendas e mitos. Desde crianças, entram em contato com o passado através de peças cerâmicas que brotam do chão, tão naturalmente quanto a floresta, reavivando na consciência coletiva a existência dos primitivos barés.

As imagens que registramos não retratam apenas continuidades históricas e culturais. Em muitas sobressaem as diferenças em relação ao tempo em que se deu a expedição de Chagas. Documentamos, por exemplo, a urbanização de populações que viviam dentro da mata, atreladas ao sistema dos barracões desenvolvido pelos proprietários de terras da Amazônia, providas do mínimo essencial para a sobrevivência: sal, açúcar, café, linha e anzol, uma arma para caçar, rede para dormir, e os instrumentos necessários para extrair produtos naturais da floresta. Com a queda dos preços pagos por estes produtos - a seringa, a balata, a castanha e a piaçava, sobretudo -, tiveram de migrar para as concentrações urbanas sem, contudo, saberem ao certo o que iam buscar ali.

$\mathrm{Na}$ época em que Carlos Chagas passou por Santa Isabel, esta se resumia a um punhado de casas ocupadas por três ou quatro negociantes com suas famílias. Localizavase numa ilha - 'Ilhinha' chamam-na hoje - na confluência de dois braços do rio Negro, bem defronte à cidade atual. Em 1991, o município de Santa Isabel possuía 15.421 habitantes. Além das roças de subsistência, da criação de pequenos animais e do pescado, as únicas atividades que movimentam a economia local são o comércio, representado por três ou quatro casas que negociam a pequena produção extrativista. A prefeitura é responsável pela quase totalidade dos empregos gerados no município.

No começo deste século, era o ponto terminal dos vapores da Casa J. G. de Araújo, que detinha o monopólio do comércio na região. Segundo Chagas, faziam apenas uma viagem por mês. Todas as crianças examinadas pelo cientista apresentavam infecção malárica crônica. E em muitas foram encontrados sinais de ancilostomose. O quadro que encontramos em 1995 é mais complexo: além da velha e temida malária, aparecem as infecções respiratórias e as doenças diarréicas agudas, que atacam principalmente as crianças. As condições de vida vão se degradando na mesma proporção em que aumenta a população da cidade. Sem água tratada, sem rede de esgotos, sem tratamento de lixo, sem médicos nem educação, os caboclos da Amazônia vêem passar muito longe a qualidade primordial da sociedade burguesa do Ocidente: a cidadania.

A simultaneidade de traços pertencentes a tempos históricos distintos desperta no pesquisador a sensação de déjã vu, de uma cruel repetição de processos e mazelas sociais. Por outro lado, o encontro com esta realidade tão diversa daquela com que lida habitualmente favorece uma atitude menos preconcebida, mais aberta ao entendimento da pluralidade de experiências e representações, como as que elaboram as populações locais para enfrentar seu presente e construir sua história.

Numa primeira etapa, em 1991, a equipe multidisciplinar do projeto 'Revisitando a Amazônia de Carlos Chagas: da borracha à biodiversidade' visitou o rio Juruá. Em 1995, 
a vice-presidência de Produção e Desenvolvimento Tecnológico da Fundação Oswaldo Cruz (Fiocruz) incorporou-se ao projeto, e o Escritório Regional de Manaus, da mesma fundação, assumiu a coordenação geral. A segunda fase englobou viagens pelos vales dos rios Negro e Branco, Purus e Acre. No trecho dos rios Negro e Branco estiveram profissionais da Escola Nacional de Saúde Pública (ENSP) e do Hospital Evandro Chagas, ambos da Fiocruz. Várias instituições da Amazônia participaram: o Instituto de Medicina Tropical de Manaus, a Universidade do Amazonas, o Instituto Nacional de Pesquisas da Amazônia e o Museu Paraense Emílio Goeldi.

Um dos resultados da segunda etapa do projeto é o álbum fotográfico Revisitando a Amazônia de Carlos Chagas: expediçâo aos rios Negro e Branco refaz percurso de Carlos Chagas em 1913 (Santos; Thielen; Medeiros; Reis; Souza, 1996), do qual provêm as imagens que reproduzimos a seguir.

\section{Fernando Dumas dos Santos e Eduardo Thielen Pesquisadores da Casa de Oswaldo Cruz}

\section{REFERÊNCIAS BIBLIOGRÁFICAS}

Albuquerque, M.; Alves, F. P.; Benchimol, J.; Santos, F. D.; Santos, R. A. dos; Thielen, E. V.; Weltman, W. L. et alii. 1991

Cruz, Oswaldo 1913

Galvão, E. 1979

Loureiro, Antônio 1989

Reis, Arthur

Cézar Ferreira 1965

Santos, Antônio Maria de Souza e Lima, Margarida Elizabeth de Mendonça 1991

Santos, F. D. dos; Thielen, E. V.; Medeiros, A.; Reis, R.; Souza, F. 1996

Souza, Márcio 1977

Thielen, Eduardo V. 1992
A ciência a caminbo da roça: imagens das expediçôes cientificas do Instituto Oswaldo Cruz ao interior do Brasil entre 1911 e 1913.

Rio de Janeiro, Casa de Oswaldo Cruz/Fiocruz.

Relatório sobre as condições médico-sanitárias do vale do Amazonas. Rio de Janeiro, Typographia Jornal do Commercio.

Encontro de sociedades: indios e brancos no Brasil. Rio de Janeiro, Paz e Terra.

O Amazonas na época imperial. Manaus, T. Loureiro Ltda.

'O vale do rio Negro'. Em Pedro Calmon, De Tupan a Cristo: jubileu de ouro das missões salesianas do Amazonas. Manaus, Missões Salesianas do Amazonas.

'Medicina tradicional e ocidental no Alto rio Negro. O papel dos rezadores em São Gabriel da Cachoeira'. Em Dominique Buchillet, Medicinas tradicionais e medicinas ocidentais na Amazônia. Belém, CEJUP.

Revisitando a Amazônia de Carlos Chagas: expedição aos rios Negro e Branco refaz percurso de Carlos Chagas em 1913. Rio de Janeiro, Casa de Oswaldo Cruz/Fiocruz, 112 p.

A expressão amazonense: do colonialismo ao neocolonialismo. São Paulo, Alfa-Ômega.

Imagens da saúde do Brasil: a fotografia na institucionalização da saúde pública. Tese de mestrado, Pontifícia Universidade Católica de São Paulo. 


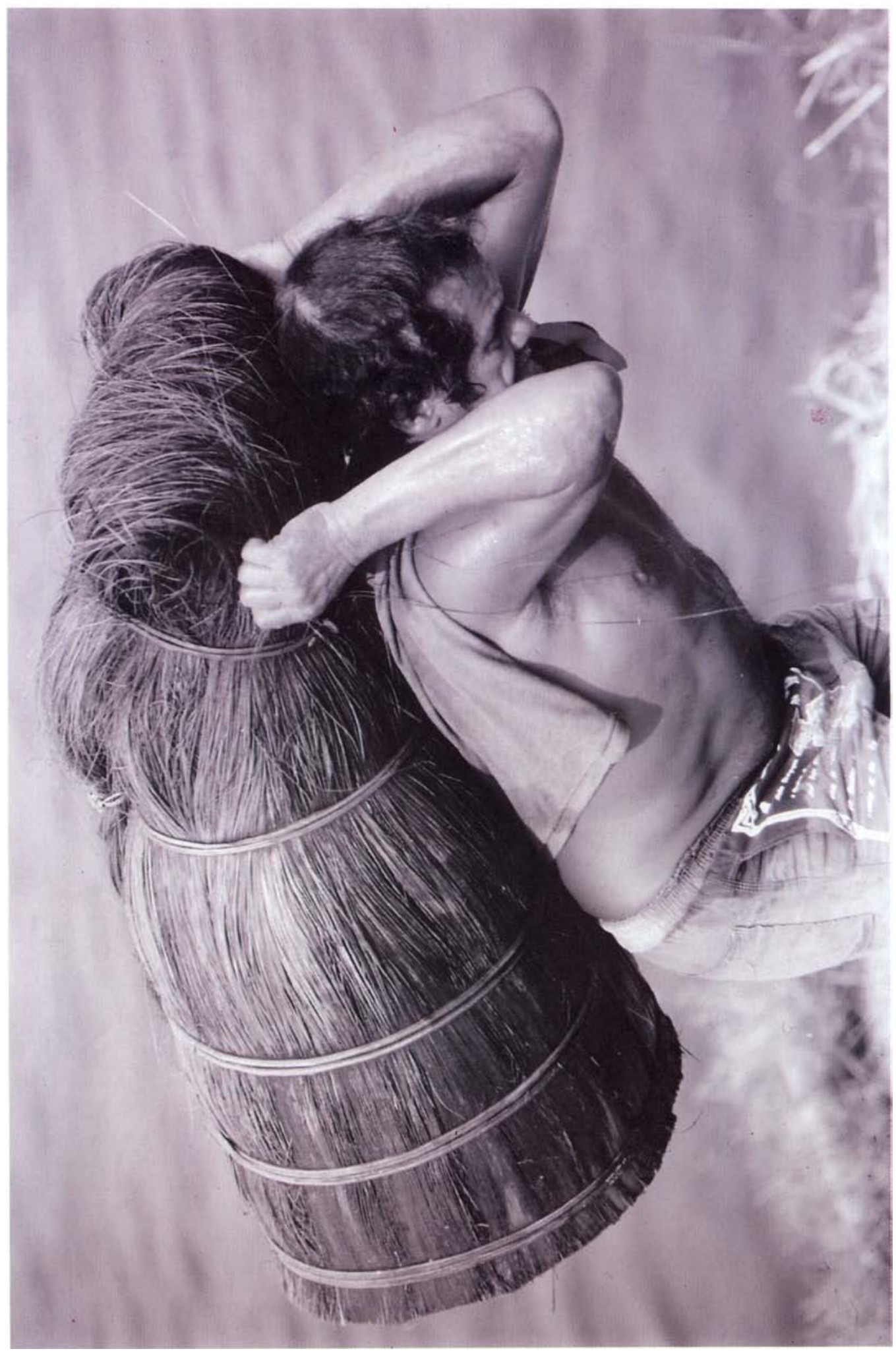

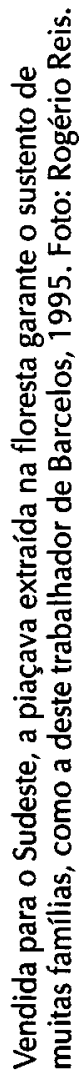




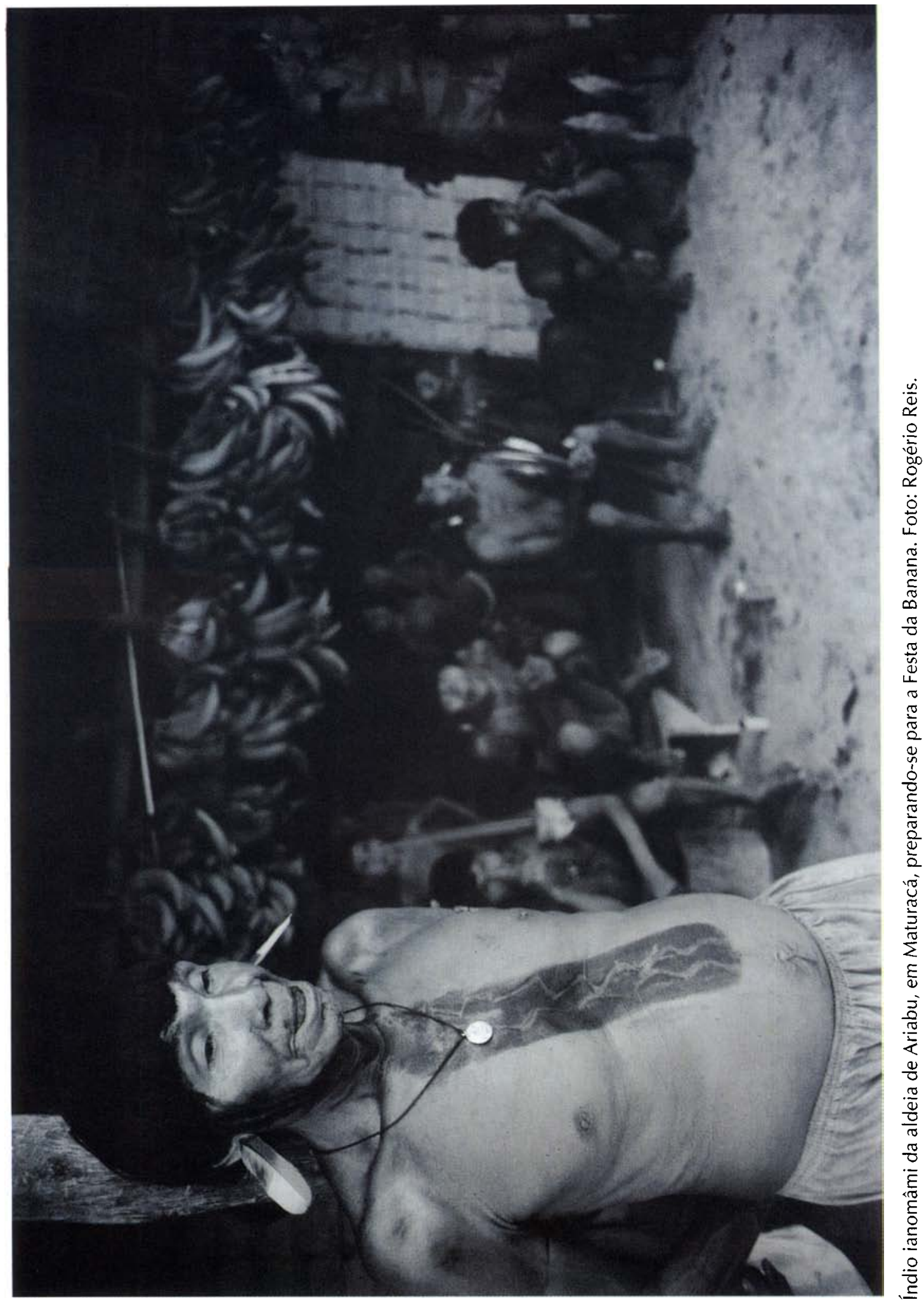




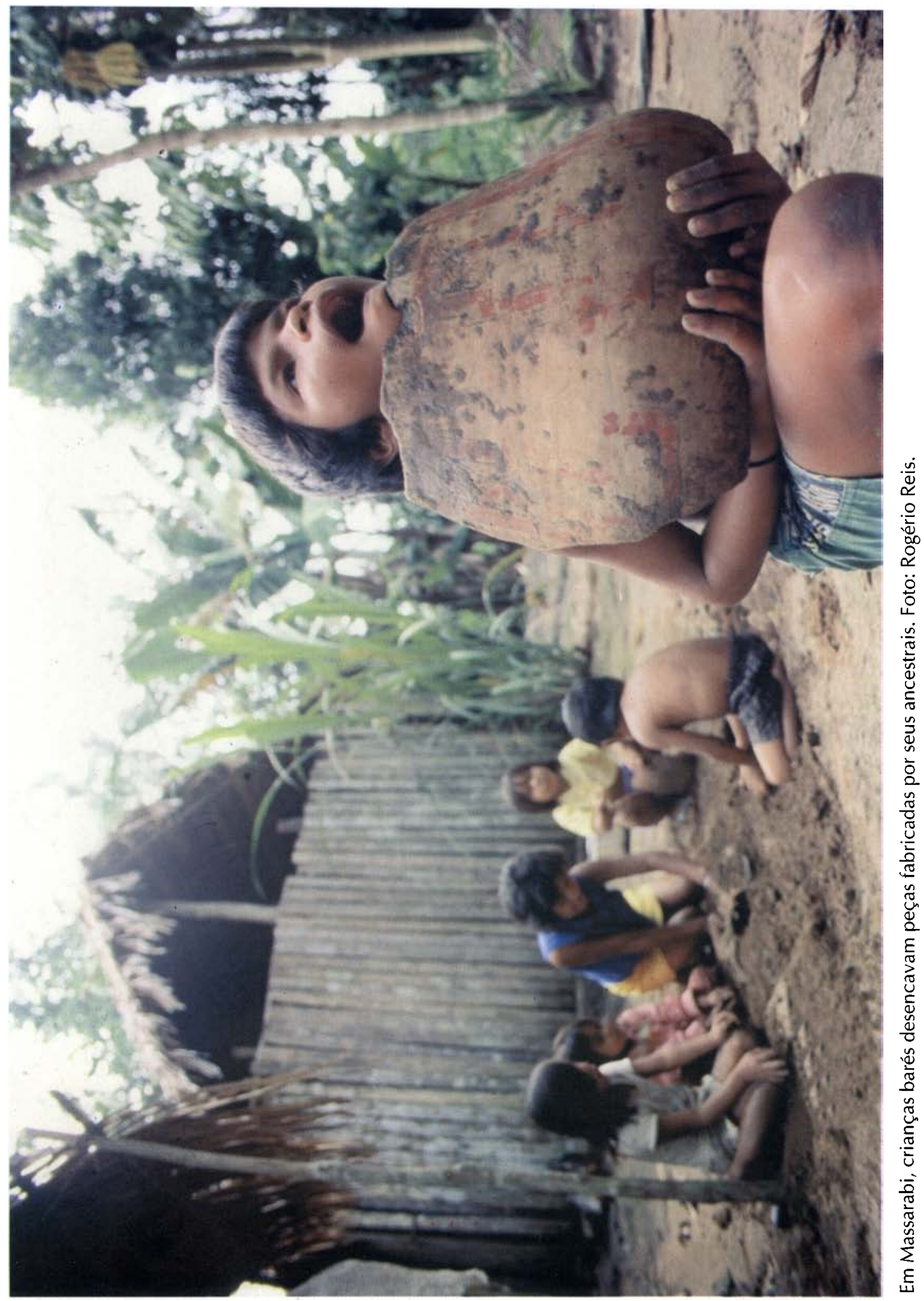




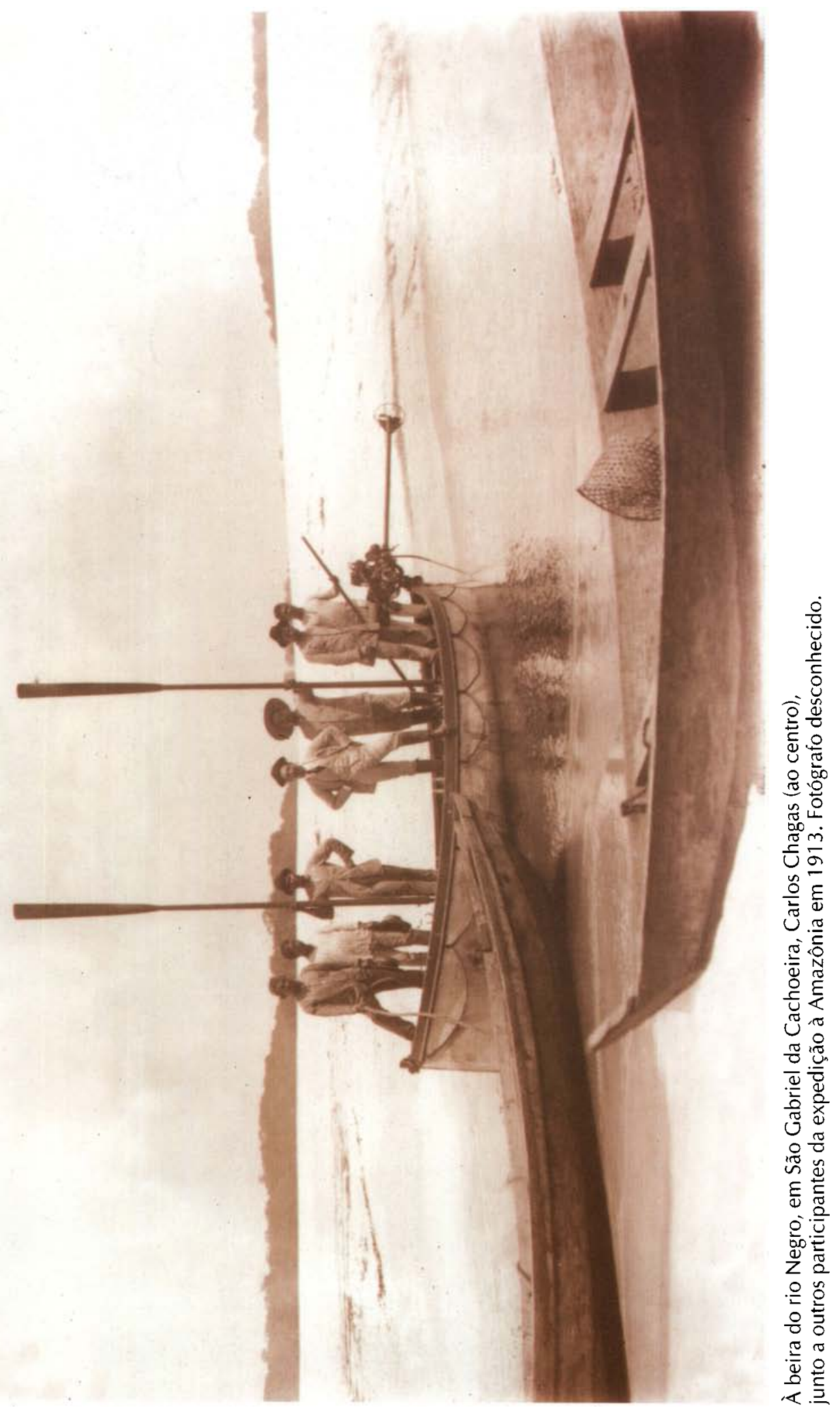




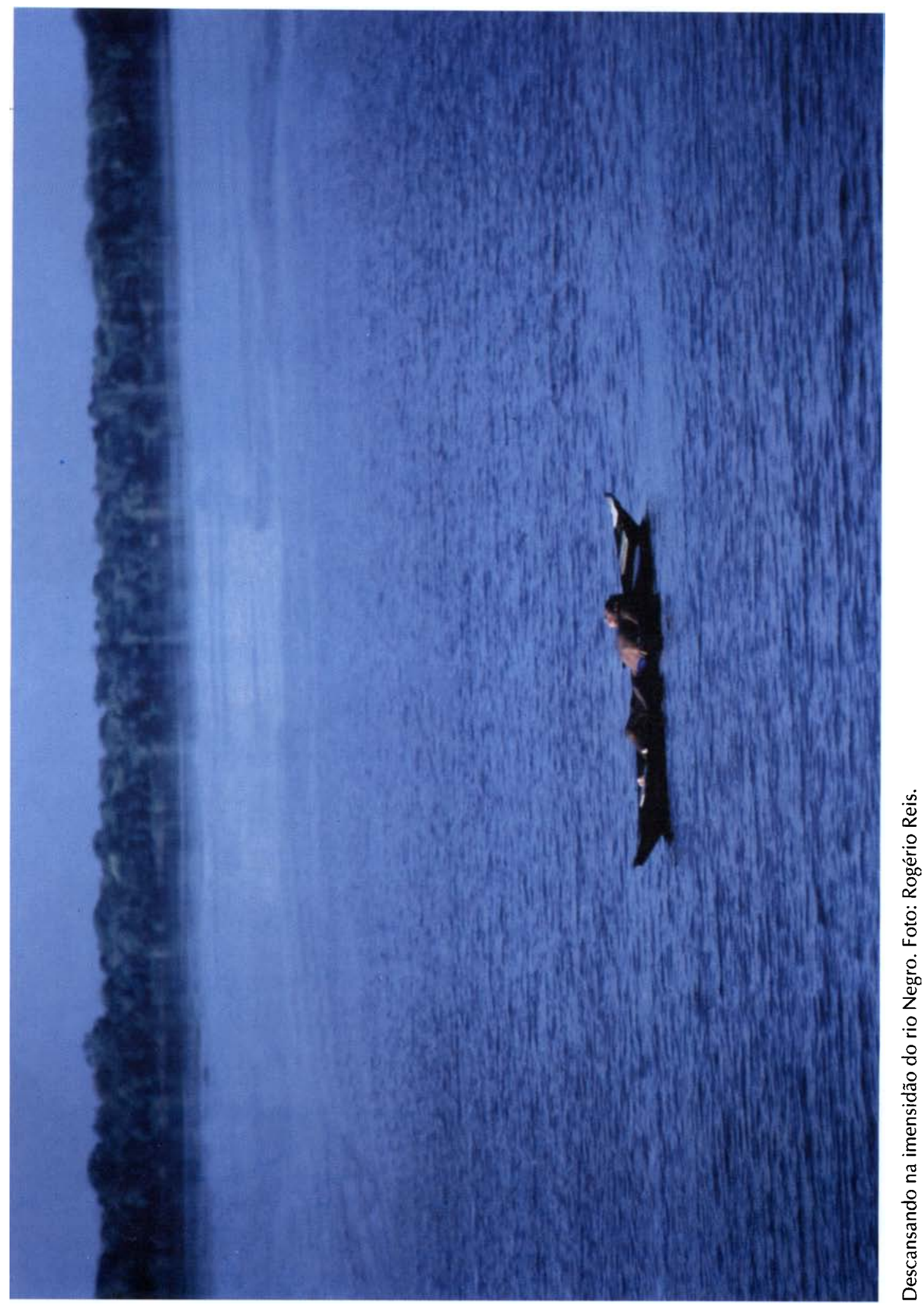




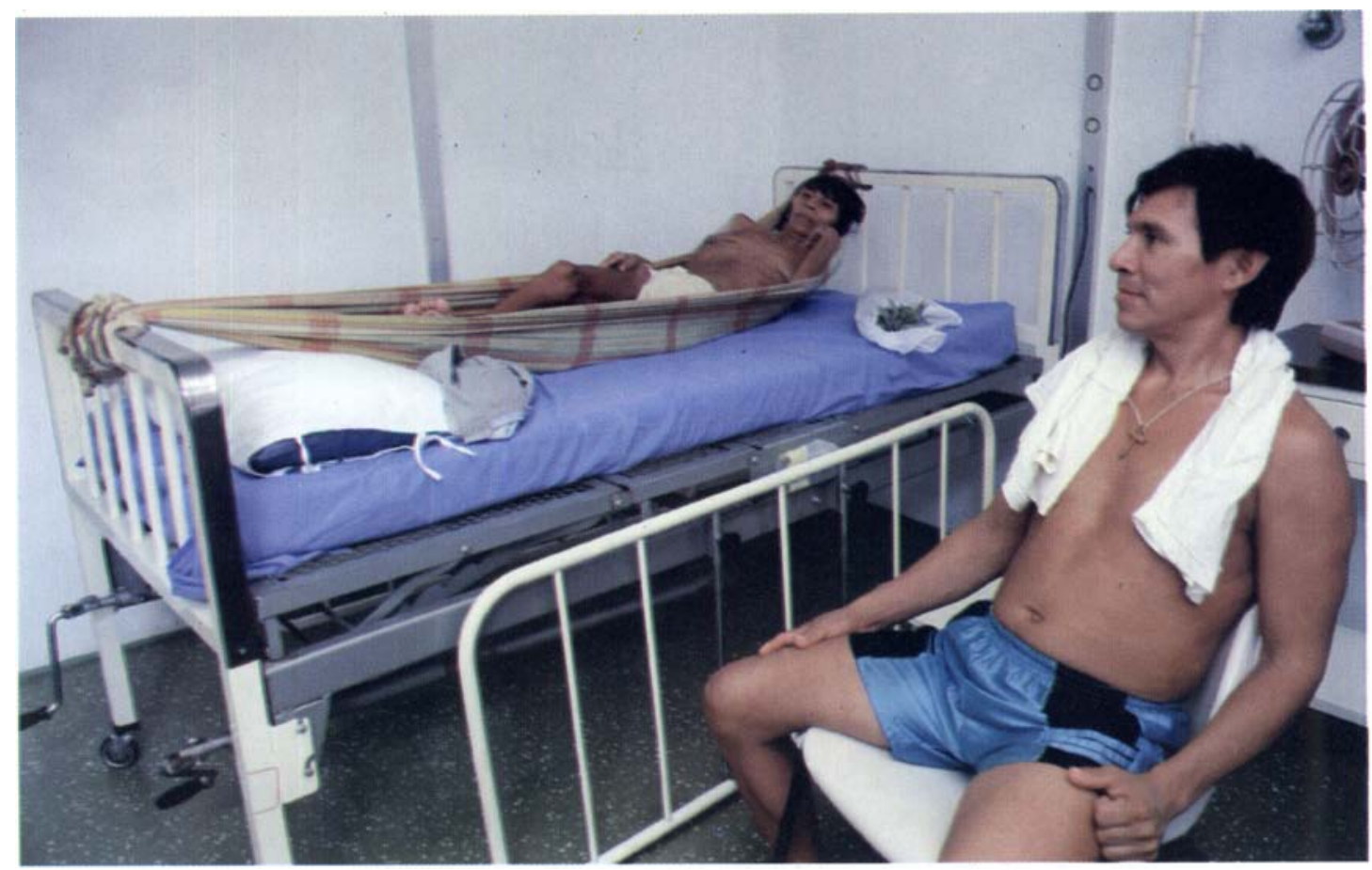

Internada com malária no hospital militar de São Gabriel da Cachoeira, índia ianomâmi não abandona sua rede. Foto: Rogério Reis.

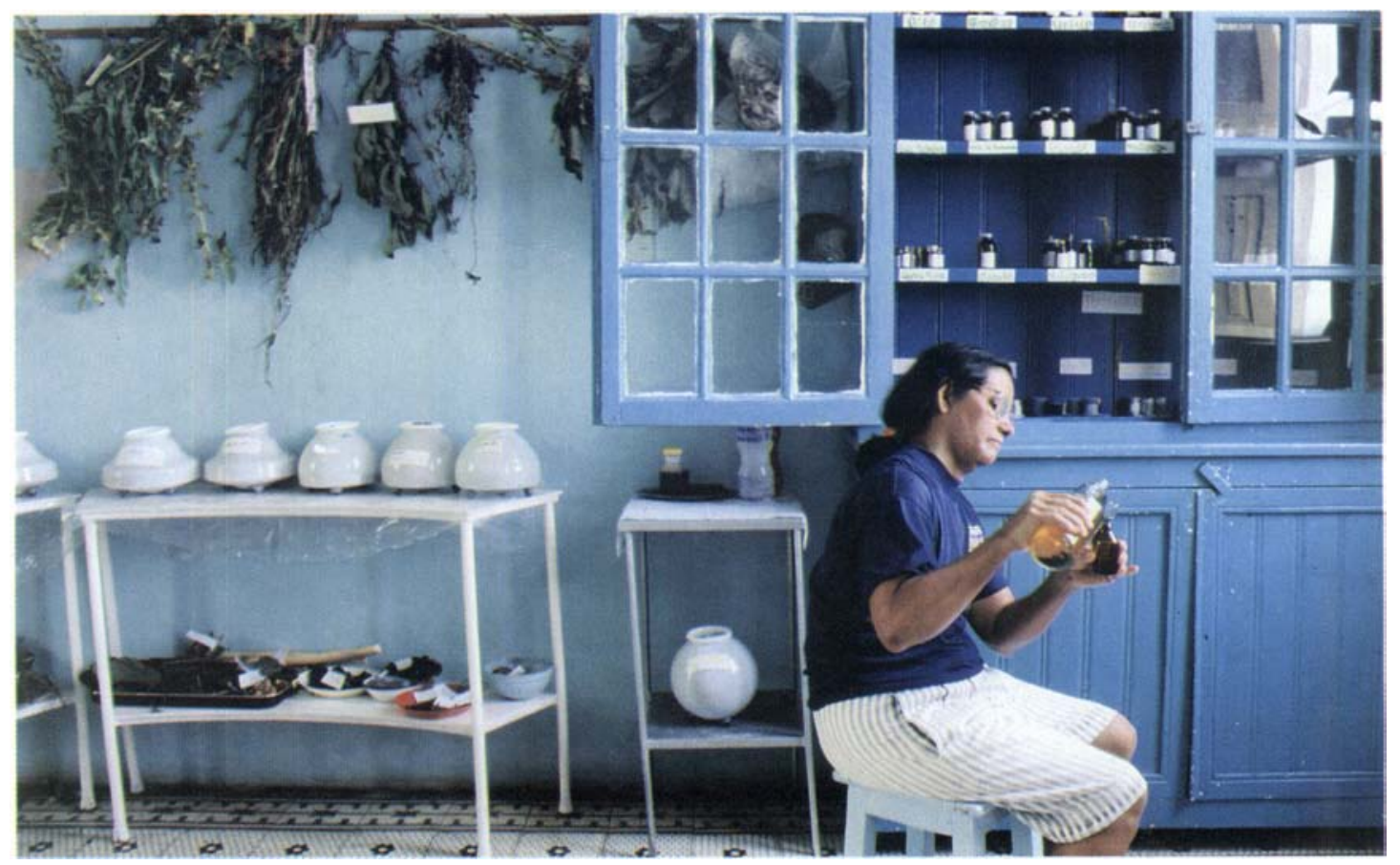

Na Farmácia Caseira de Barcelos, Maria do Carmo prepara xaropes e tinturas com plantas medicinais. Foto: Rogério Reis. 

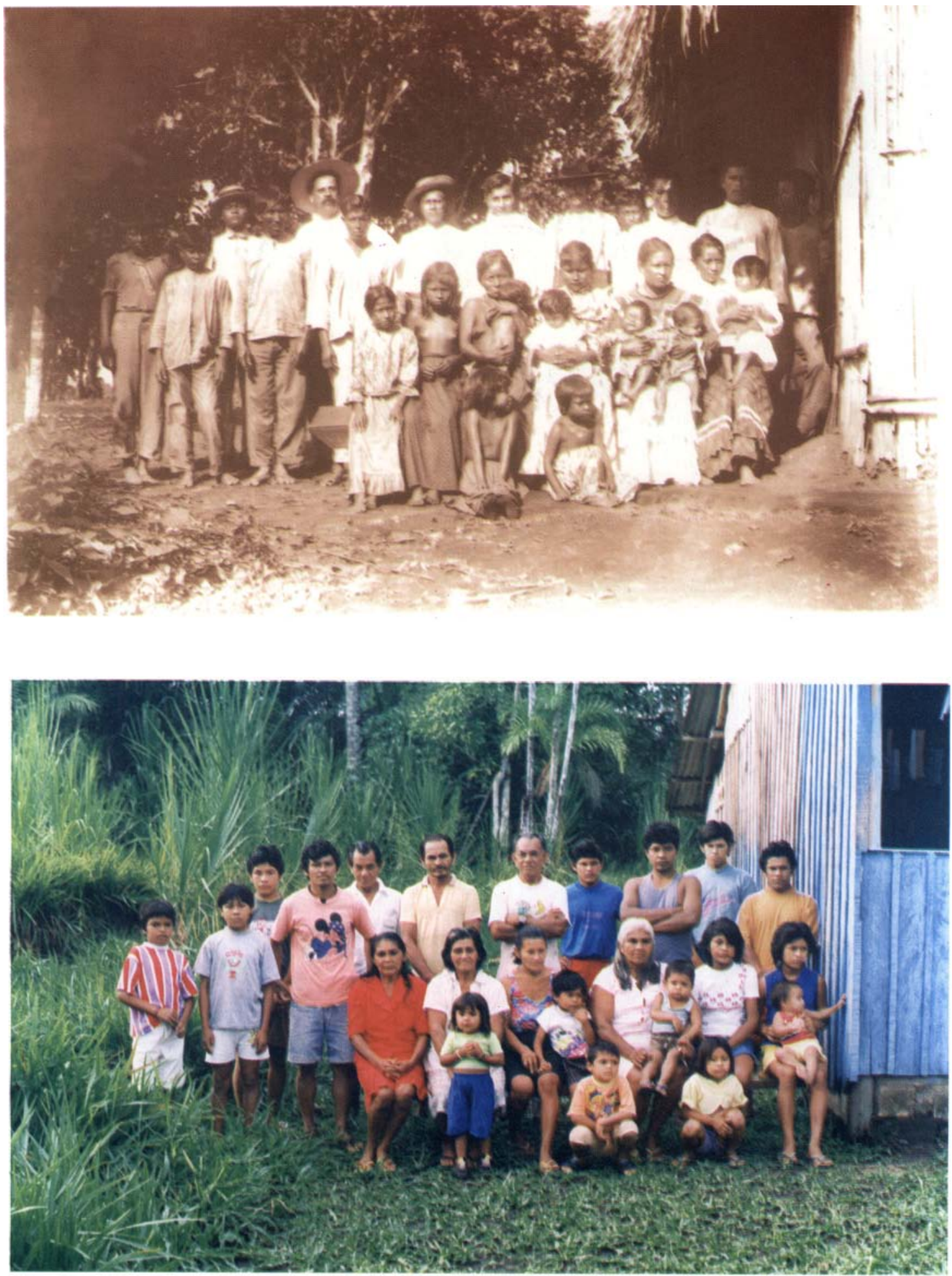

Em 18.8.1995, os barés da ilha de Massarabi reuniram-se para uma foto, como seus antepassados, em 1913.

Foto histórica: Acervo da Casa de Oswaldo Cruz. Atual: Flávio de Souza. 


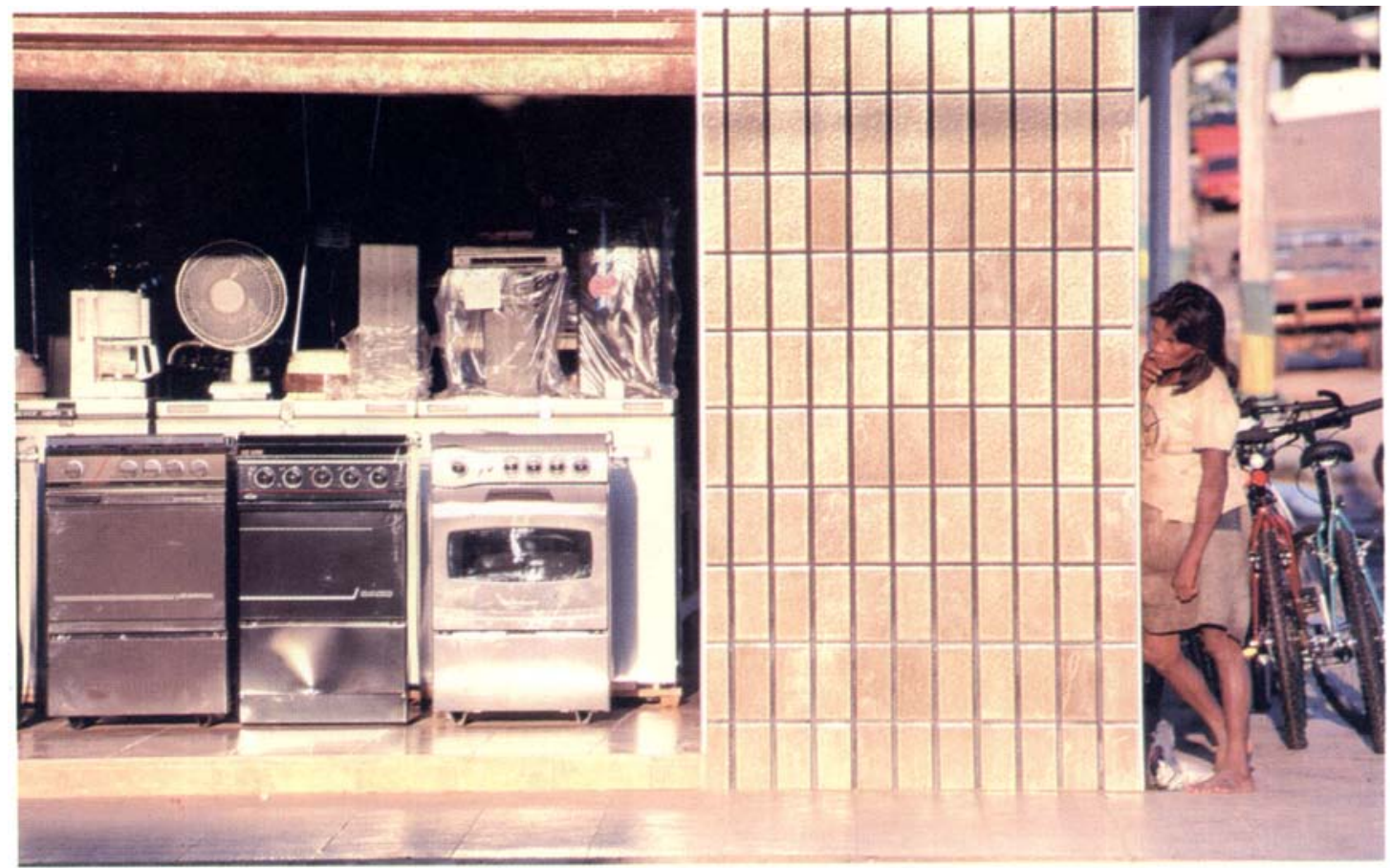

Índia ianomâmi no centro de São Gabriel da Cachoeira. Foto: Rogério Reis.

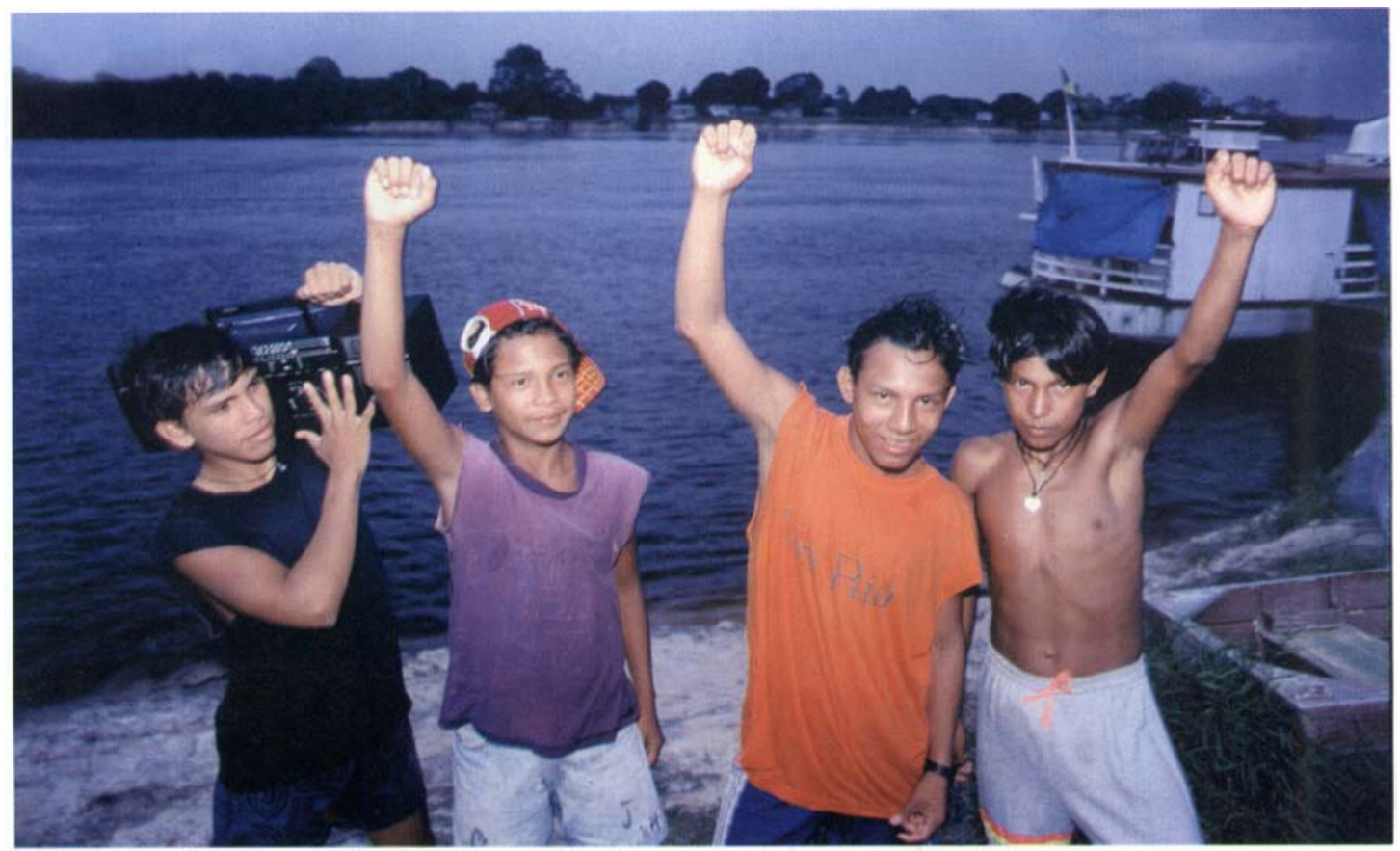

Uma das galeras de adolescentes de Santa Isabel do Rio Negro. O padre Carlos Zuchetti atribui as constantes brigas ao preconceito: "Os que nasceram em Santa Isabel acham que os ianomâmi são bichos-do-mato. E os ianomâmi acham que são os verdadeiros homens, que todos os outros são estrangeiros." Foto: Rogério Reis. 